\title{
3d Transition metal decorated B-C-N composite nanostructures for efficient hydrogen storage: A first-principles study
}

\author{
S BHATTACHARYA, C MAJUMDER ${ }^{\dagger}$ and G P DAS* \\ Department of Materials Science, Indian Association for the Cultivation of Science, Kolkata 700 032, India \\ ${ }^{\dagger}$ Chemistry Division, Bhabha Atomic Research Centre, Mumbai 400 085, India
}

\begin{abstract}
Ti decorated BC_4N nanotube has been studied using first-principles density functional approach, to explore the storage of molecular hydrogen. It combines the advantages of carbon nanotube, together with the thermal stability of $\mathrm{BN}$ nanotube. The local structural unit of $\mathrm{BN}_{3}$ and $\mathrm{NB}_{3}$ linked with $\mathrm{B}-\mathrm{N}$ bonds are responsible for the extra stability of $\mathrm{BC}_{-} 4 \mathrm{~N}$ nanotube as compared with $\mathrm{CNT}$. While the host carbon nanotube is metallic, the substitutional doping of $B$ and $N$ with a large enough concentration (33\%) turns it to semiconducting. Endohedral decoration, although energetically favourable, encounters a rather high barrier height of $\sim 4 \mathrm{eV}$, as obtained from our nudge elastic band calculation of the minimum energy path. Exohedral $\mathrm{Ti} @ \mathrm{BC}_{4} \mathrm{~N}$ can bind up to four $\mathrm{H}_{2}$ molecules. For full Ti coverage, the system can absorb up to $5.6 \mathrm{wt} \%$ of hydrogen. $A b$ initio molecular dynamics simulation reveals that at $500 \mathrm{~K}$ hydrogen gets released in molecular form. We believe that this novel composite nanotube, functionalized by $\mathrm{Ti}$ atoms from outside, serves as a promising system for hydrogen storage.
\end{abstract}

Keywords. Hydrogen storage; B-C-N composite nanotube; density functional; electronic structure; molecular dynamics.

\section{Introduction}

Hydrogen is considered to be one of the best alternative and renewable fuels (Schlappbach and Züttel 2001; Züttel 2003,2004 ) because of its abundance, easy synthesis, and nonpolluting nature when used in fuel cells. For the advancement of hydrogen storage as fuel cell technologies, storing safe and cost effective pure hydrogen is the biggest challenge, as it must meet the basic requirements of high gravimetric and volumetric density together with fast kinetics and favourable thermodynamics (Schlappbach and Züttel 2001). For commercial applications, it is necessary to develop novel materials that can reversibly store molecular hydrogen with a gravimetric efficiency of $6 \mathrm{wt} \%$, the target set by the Department of Energy, USA (DOE Report), and at the same time possess acceptable desorption kinetics under ambient conditions. Presently, the methods for storage of hydrogen as compressed gas or in the liquid form do not meet the practical requirements. Alternative options, by utilizing suitable solid state hydriding and dehydriding reactions in low-Z complex hydrides are being extensively studied, albeit with limited success so far. Desorption of hydrogen at a moderate temperature is, in some sense, more important than adsorption on it. Any light metal is known to adsorb hydrogen to reasonably high wt\%. However, on metal surfaces,

*Author for correspondence (msgpd@iacs.res.in) hydrogen undergoes dissociative chemisorptions, which results in the strong metal-hydrogen bonds. This is the primary reason why all these metal hydrides, where hydrogen is attached in atomic form, show slow kinetics for adsorption and desorption processes. Storage of hydrogen in molecular form is advantageous due to its fast kinetics as well as low binding energy that could lead to the possibility of desorption of hydrogen molecule at low temperature (Darkrim et al 2002; David 2005; Jacoby 2005; Orimo et al 2007; Sakintuna et al 2007; Wolverton et al 2008).

Particularly promising from the point of view of hydrogen storage are porous materials such as clathrates (Hu and Ruckenstein 2006; Struzhkin et al 2007), zeolites (Logar and Kaucic 2006), metal-organic frameworks (Rowsell and Yaghi 2005; Hirscher and Panella 2007) and various carbon based nanostructures, such as fullerenes and nanotubes (Dillon and Heben 2001; Meregalli and Parrinello 2001; Williamson et al 2004). These cage-like structures have high stability, light weight (leading to high gravimetric efficiency), large surface-to-bulk ratio and possibility of funtionalization with appropriate metals. Hence these systems serve as ideal materials for storage of molecular hydrogen endohedrally or exohedrally. We shall briefly discuss in the next section the advantages as well as shortcomings of single walled carbon nanotubes (CNT) (Dillon et al 1997) and their isoelectronic counterparts such as boron nitride nanotubes (BN-NT) (Ma et al 2002) for hydrogen storage. 


\section{Hydrogen storage in $\mathrm{CNT}$ and $\mathrm{BN}-\mathrm{NT}$}

Early experiments on carbon nanotubes are not so encouraging since the hydrogen storage capacity reported are less than $1 \%$ or so (Tibbetts et al 2001; Shiraishi et al 2003). Kajiura et al (2003) measured the hydrogen storage capacity of five types of commercially available carbon materials with different nanostructures at up to $8 \mathrm{MPa}$ at room temperature. Using an apparatus where the error in the gravimetric density was less than $0.04 \mathrm{wt} \%$, they reported the highest storage capacity to be $0.43 \mathrm{wt} \%$. Recent theoretical study indicates that high hydrogen content in the pure carbon nanotubes cannot be achieved through physical sorption (Blase et al 1994). More recently, Yildirim and Ciraci (2005) have shown from their first principles calculations that functionalizing the CNT with suitable transition metal atoms could lead to high capacity hydrogen storage ( $\sim 8 \mathrm{wt} \%$ ) along with the possibility of some interesting hydrogen desorption of the system. However, tendency of a normal CNT to get oxidized around $600^{\circ} \mathrm{C}$, rejects the practical possibility of using this TM functionalized CNT as far as high capacity hydrogen storage is concerned.

Because of these shortcomings of carbon nanotube, efforts have been shifted towards non-carbonic materials composed of light elements such as B and N. B-N nanostructures are analogous to their carbon counterparts and offer many advantages. For example, B-N nanotubes are stable up to $1000^{\circ} \mathrm{C}$. In addition to their heat resistance in air and structural stability, B-N nanotubes are semiconducting with wide bandgaps $(5.5 \mathrm{eV})$ that is nearly independent of tube diameter or helicity. With the advancement in synthesis techniques, many novel forms of B-N nanostructures, such as nanotubes (Chopra et al 1995; Ma et al 2002), bamboo-like wires (Oku et al 2004a), nanocages (Oku et al 2004b), and nanocapsules (Oku and Narita 2002) have been discovered. Furthermore, several authors have also studied the hydrogen uptake and reversibility issues of B-N nanostructures (Ma et al 2002; Narita and Oku 2002; Oku and Narita 2002; Oku et al 2004a, b). However, if we look at the practical implementation of these kinds of structures for hydrogen storage, these have limited success. This is because of (a) the stability of most of these cage like B-N nanostructures at room temperature (Sun et al 2005) and (b) the abnormally high hydrogen-desorption temperature from the B-N nanotubes for its extra thermal stability (Ma et al 2002).

\section{B-C-N composite nanotube: Motivation and a wish list of properties}

Is it possible to exploit the thermal stability of BN nanotube, together with the advantages of Ti functionalized CNT? The aim of the present work is precisely to achieve this by designing a Ti functionalized $\mathrm{B}-\mathrm{C}-\mathrm{N}$ nanocomposite, viz. $\mathrm{BC}_{4} \mathrm{~N}$ nanotube, as a possible $\mathrm{H}$-storage material. $\mathrm{B}_{x} \mathrm{C}_{y} \mathrm{~N}_{z}$ nanostructures have been studied both experimentally and theoretically (Weng-Sieh et al 1995; Sen et al 1998). Recently, $\mathrm{BC}_{4} \mathrm{~N}$ nanotubes have been experimentally synthesized (Raidongia et al 2008) and found to be semiconducting in nature with a very high thermal stability. The local structural unit of $\mathrm{BN}_{3}$ and $\mathrm{NB}_{3}$ linked with $\mathrm{B}-\mathrm{N}$ bonds are responsible for the extra stability, as compared to its host carbon nanotube. While the host carbon nanotube is metallic, the substitutional doping of $\mathrm{B}$ and $\mathrm{N}$ with a large enough concentration $(33 \%)$ turns it to a semiconductor. The synthesis, characterization and various properties of $\mathrm{BC}_{4} \mathrm{~N}$ nanotubes are described in detail by Raidongia et al (2008). What we have done is to explore how to functionalize it for storage of molecular hydrogen (Bhattacharya et al 2008).

Incidentally, there have been earlier studies of transition metal doped carbon nanotubes (Yagi et al 2004), but the motivation was to understand magnetism that got manifested in this system. However, in order to utilize functionalized nanotubes for efficient hydrogen storage, we have to address several open questions e.g.: (i) Does transition metal prefer to stay in exohedral or endohedral position of the nanotube? (ii) What is the energy barrier for the transition metal to enter into or escape from the nanotube? (iii) What happens when more transition metals are decorated in different hexagonal faces of the nanotube? (iv) How the binding energy of $\mathrm{H}_{2}$ changes during addition of more $\mathrm{H}_{2}$ in the TM-doped $\mathrm{BC}_{4} \mathrm{~N}$ nanotube both in exohedral and endohedral position? (v) As more $\mathrm{H}_{2}$ are stored, what are the changes in the geometry and electronic structure of the nanotube? (vi) Lastly, from the hydrogen storage point of view, what is the effect of the temperature on the stability of this kind of $\mathrm{B}-\mathrm{C}-\mathrm{N}$ composite nanotube? In this work, we provide a detailed study to address these questions for this novel $\mathrm{BC}_{4} \mathrm{~N}$ nanotube, and see if the storage efficiency can be improved significantly.

\section{Computational details}

Electronic structure and total energies were calculated with the Vienna $a b$ initio simulation package (VASP) (Kresse and Hafner 1994; Kresse et al 1996), based on DFT (Hohenberg and Kohn 1964; Kohn and Sham 1965). Projector-augmented wave (PAW) potentials (Blöchl 1994) were employed for the elemental constituents, viz. $\mathrm{H}, \mathrm{B}, \mathrm{C}, \mathrm{N}$ and Ti potentials which contained one, three, four, five and four valence electrons, respectively. The GGA calculation was performed with the Perdew-Wang (Perdew and Wang 1992; Perdew et al 1992) exchangecorrelation potential. The $k$-points mesh was generated by the Monkhorst-Pack (Monkhorst and Pack 1976) method and all results were tested for convergence with respect to 
the mesh size. In all calculations, self-consistency was achieved with a $0 \cdot 1 \mathrm{meV}$ convergence of total energy. For high precision calculation we used a cutoff energy of $400 \mathrm{eV}$ for plane wave basis. For obtaining the optimized ground state geometry (Pulay 1980; Press et al 1986), atomic forces were converged to less than $0.001 \mathrm{eV} / \AA$ by conjugated gradient (CG) minimization. We also performed $a b$ initio molecular dynamics (MD) simulations in order to investigate the stability of the optimized structures and desorption of hydrogen molecules from $\mathrm{Ti} @ \mathrm{BC}_{4} \mathrm{~N}$ nanotube.

\section{5. $\mathrm{BC}_{4} \mathrm{~N}$ nanotube}

\subsection{Ground state structure}

The ground state structures of $\mathrm{BC}_{4} \mathrm{~N}$ nanotubes having different chirality, viz. $(6,0)$ and $(8,0)$ zigzag nanotubes, and $(6,6)$ armchair nanotube, have been investigated to be semiconducting with varying energy gaps, and all are nonmagnetic (Raidongia et al 2008). Since nanotubes with larger bandgap are likely to show stronger hydrogen adsorption (Yildirim and Ciraci 2005), we have chosen for our model study, the $(6,6)$ armchair $\mathrm{BC}_{4} \mathrm{~N}$ nanotube that shows the largest bandgap $(\sim 1.0 \mathrm{eV})$ in this family. The accuracy of our computational tool was tested by relaxing this $(6,6)$ armchair nanotube structure, that resulted in the optimized diameter of $8.3 \AA$, which is in good agreement with the available experimental value (Raidongia et al 2008). Further, to take into account the different chemical orderings of hexagons, we have cho-
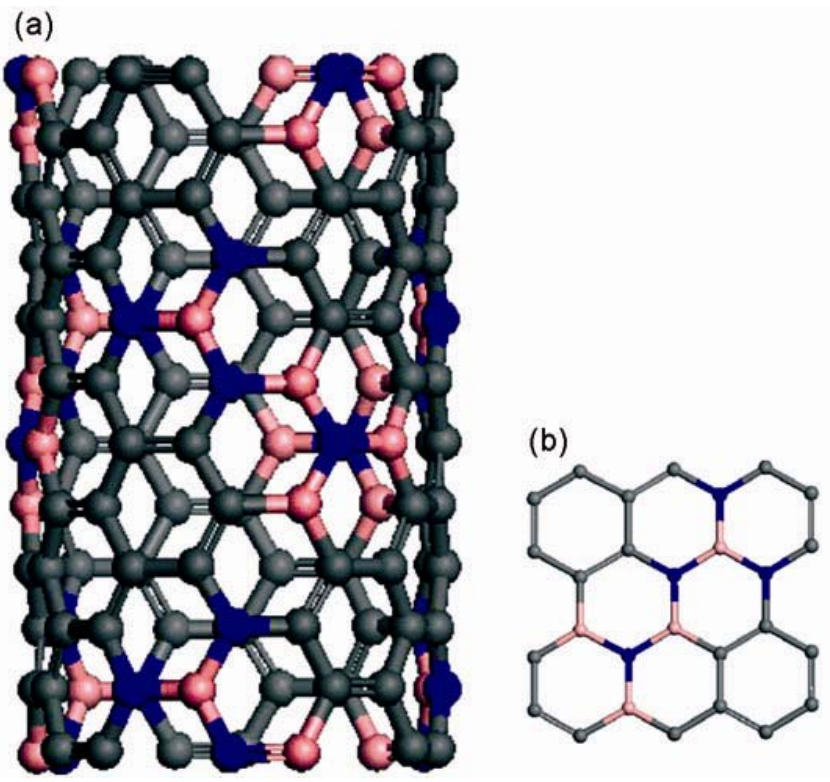

Figure 1 (Colour online). (a) Ball and stick model of pure $\mathrm{BC}_{4} \mathrm{~N}$ nanotube and (b) $\mathrm{BN}_{3}$ and $\mathrm{NB}_{3}$ connection with a $\mathrm{BN}$ bond. Pink ball $=\mathrm{B}$, blue ball $=\mathrm{N}$, dark ash ball $=\mathrm{C}$. sen the length of the nanotube to be $14.9 \AA$. The corresponding supercell that we constructed for our simulation studies contains $24 \mathrm{~B}, 96 \mathrm{C}$ and $24 \mathrm{~N}$ atoms (figure 1a).

The thermal stability of $\mathrm{BC}_{4} \mathrm{~N}$ nanotube is very high, $\sim 900^{\circ} \mathrm{C}$ (Raidongia et al 2008). Selective substitution of $\mathrm{C}$ atoms by $\mathrm{B}$ and $\mathrm{N}$ (figure 1b) make this system more stable compared to the well-known CNT. Such a composite carbon based nanotube is expected to retain the advantages of CNT, and at the same time avoid the possibility of oxidation of normal CNT. However, pure $\mathrm{BC}_{4} \mathrm{~N}$ nanotube is not a good hydrogen storage medium as it can store only up to $0.7 \mathrm{wt} \%$ of hydrogen (Raidongia et al 2008).

Therefore, we have tried to dope a $3 d$ transition metal, like $\mathrm{Ti}$, which had earlier been used to decorate other fullerene and nanotube surfaces (Yildirim and Ciraci 2005; Barman et al 2008) and thereby increase the wt\% for hydrogen storage. The specific choice of $\mathrm{Ti}$ rather than any of its $3 d$ transition metals counterparts, viz. Sc, $\mathrm{V}, \mathrm{Cr}, \mathrm{Mn}, \mathrm{Fe}$ etc is because of the fact that Ti serves the best as a dopant amongst all $3 d$ transition metals from hydrogen storage point of view (Shevlina and Guo 2006).

\subsection{Endo-vs exo-hedral Ti@BC $C_{4} N$ nanotube}

We have first tried to understand the preferred position of $\mathrm{Ti}$ on different hexagonal faces of $\mathrm{BC}_{4} \mathrm{~N}$ nanotube. It is to be noted that for all the B-C-N hexagonal faces, the mean number of valence electrons is 4 and a Ti atom also has exactly the same number of valence electrons. We placed $\mathrm{Ti}$ on the different hexagonal faces of the $\mathrm{BC}_{4} \mathrm{~N}$ nanotube either exohedrally or endohedrally, and subsequently optimized the geometry of the entire structure. Table 1 summarizes the binding energy of a Ti atom both for exohedral and endohedral positions at different hexagonal sites for $\mathrm{BC}_{4} \mathrm{~N}$ nanotube. Endohedral position turns out to be energetically favourable compared to exohedral, and amongst all the hexagonal faces the 6C hexagonal face (i.e. with all six carbon atoms in the hexagonal ring) is energetically most stable (see table 1). As far as the site preference of the $\mathrm{Ti}$ is concerned, the on-top and bridge positions are unstable. This has been verified by fixing the initial position of $\mathrm{Ti}$ on top or bridge site of the nanotube, which on relaxation shows that $\mathrm{Ti}$ eventually moves to the nearest $6 \mathrm{C}$ hexagon site. In order to ascertain the exohedral versus endohedral Ti-capping in $\mathrm{Ti} @ \mathrm{BC}_{4} \mathrm{~N}$ nanotube, a crucial factor is the energy barrier that the $\mathrm{Ti}$ atom has to cross while going from 'outside' to 'inside' of the nanotube or vice versa. That means even though Ti prefers energetically endohedral rather than exohedral position, a complete understanding is lacking unless and until one can find the actual barrier height required for $\mathrm{Ti}$ atom to enter inside the nanotube. In order to estimate this barrier height for a Ti atom, we have carried out a detailed study with the 
help of nudge elastic bands (NEB) method where we tried to move a Ti atom slowly from outside to inside of the $\mathrm{BC}_{4} \mathrm{~N}$ nanotube in six steps. We found that the approximate barrier height is $4 \mathrm{eV} / \mathrm{Ti}$ atom (figure 2). This signifies that, it is energetically costly to substitute a Ti atom inside the nanotube.

\section{$5.3 \quad H$-storage in Ti@B $\mathrm{BC}_{4} \mathrm{~N}$}

The results of adsorption of hydrogen in molecular form have been summarized in table 2 both for exohedral and endohedral positions (figure 3 ). It is to be noted from table 2 that in exohedral and endohedral Ti $a \mathrm{BC}_{4} \mathrm{~N}$, each of the $\mathrm{Ti}+$ ion can get attached to $4 \mathrm{H}_{2}$ molecules. In the endohedral case, the last $\mathrm{H}_{2}$ molecule gets physisorbed with $\mathrm{Ti}$ atom with a very week binding energy value of

Table 1. Binding energy values and number of inequivalent hexagons for different adsorption sites of $\mathrm{Ti}$ atoms both in exohedral and endohedral positions of $\mathrm{BC}_{4} \mathrm{~N}$ nanotube. Different hexagon faces have been designated as $\mathrm{B}_{n 1} \mathrm{C}_{n 2} \mathrm{~N}_{n 3}$ with $n_{1}+n_{2}+$ $n_{3}=6 . N_{\text {hex }}$ is the number of inequivalent hexagons (total 57) in $\mathrm{BC}_{4} \mathrm{~N}$ nanotube of length, $14.9 \AA$.

\begin{tabular}{lccc}
\hline & \multicolumn{3}{c}{ Binding energy (eV/Ti atom) } \\
\cline { 3 - 4 } Different hexagonal faces & $N_{\text {hex }}$ & Endohedral & Exohedral \\
\hline 6C & 18 & $-2 \cdot 49$ & $-2 \cdot 18$ \\
1B-5C & 3 & $-2 \cdot 30$ & $-1 \cdot 87$ \\
$1 \mathrm{~N}-5 \mathrm{C}$ & 6 & $-2 \cdot 04$ & -1.92 \\
2B-1N-3C & 6 & $-2 \cdot 20$ & $-2 \cdot 04$ \\
2B-2N-2C & 9 & -1.95 & -1.57 \\
2N-1B-3C & 9 & $-1 \cdot 81$ & -1.52 \\
1B-1N-4C & 6 & $-2 \cdot 07$ & -1.70 \\
\hline
\end{tabular}

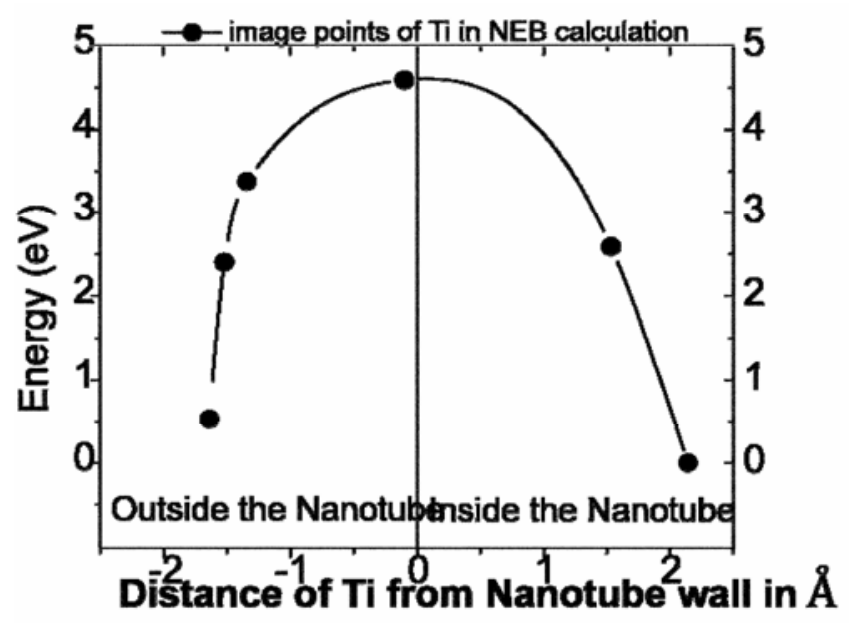

Figure 2. Barrier height for Ti atom to move from outside to inside of the $\mathrm{BC}_{4} \mathrm{~N}$ nanotube as calculated by nudge elastic band (NEB) method (see text for details). The estimated barrier height is $\sim 4 \mathrm{eV}$. $\sim 0.04 \mathrm{eV}$, while for the exohedral case the binding energies lie exactly in the energy window desired for hydrogen storage. The bond length details for both exohedral and endohedral $\mathrm{Ti} @ \mathrm{BC}_{4} \mathrm{~N}$ nanotube with consecutive $\mathrm{H}_{2}$ addition is given in table 3 , where the $\mathrm{Ti}-\mathrm{H}$ distance is referred to as the distance between $\mathrm{Ti}$ atom and nearest $\mathrm{H}$ atom of the $\mathrm{H}_{2}$ molecule. But from our NEB results we may infer that endohedral $\mathrm{Ti}$ decoration is practically a difficult task. So in order to increase the weight percent for hydrogen storage, we have decorated this $\mathrm{BC}_{4} \mathrm{~N}$ nanotube exohedrally with $\mathrm{Ti}$ atoms on all the $6 \mathrm{C}$ hexagonal sites and optimized the geometry of the decorated structure. The final optimized structure is shown in figure 4a. We infer from this that since each $\mathrm{Ti}$ atoms can adsorb $4 \mathrm{H}_{2}$ molecules, altogether $72 \mathrm{H}_{2}$ molecules can be adsorbed by this system with an estimated $5.60 \mathrm{wt} \%$ of hydrogen storage. Now a fully relaxed self-consistent calculation on $\mathrm{Ti}_{18} @ \mathrm{BC}_{4} \mathrm{~N}+72 \mathrm{H}_{2}$ is computationally quite demanding. So we have checked with two adjacent $\mathrm{Ti}$ atoms, i.e. $\mathrm{Ti}_{2} @ \mathrm{BC}_{4} \mathrm{~N}$ and found that this system can adsorb $8 \mathrm{H}_{2}$ molecules (figure $4 \mathrm{~b}$ ). With this result, we can conclude that the final Ti decorated $\mathrm{BC}_{4} \mathrm{~N}$ system can adsorb up to $5.60 \mathrm{wt} \%$ of hydrogen.

\subsection{Electronic structure}

In figure 5 we have illustrated the partial density of states of pure $\mathrm{BC}_{4} \mathrm{~N}, \mathrm{Ti} @ \mathrm{BC}_{4} \mathrm{~N}$ and $\mathrm{Ti} @ \mathrm{BC}_{4} \mathrm{~N}+n \mathrm{H}_{2}[n=1,2,3$, $4]$, respectively. We notice from this that while the host carbon nanotube is metallic, the substitutional doping of $\mathrm{B}$ and $\mathrm{N}$ with a large enough concentration (33\%) can make it semiconducting. Therefore, we may consider this $\mathrm{B}-\mathrm{C}-\mathrm{N}$ composite nanotube as an interface of two well known nanotubes viz. carbon nanotube and $\mathrm{B}-\mathrm{N}$ nanotube. The local structural unit of $\mathrm{BN}_{3}$ and $\mathrm{NB}_{3}$ linked with $\mathrm{B}-\mathrm{N}$ bonds (figure $\mathrm{lb}$ ) is the main reason of it to have an extra stability as compared with its host carbon nanotube. This difference in the nature of bonding is obvious from the charge density contour plot (figure 6a), which shows the variation in the electron densities between the $\mathrm{C}-\mathrm{C}$ bond vis-à-vis $\mathrm{B}-\mathrm{C}, \mathrm{N}-\mathrm{C}$ and $\mathrm{B}-\mathrm{N}$ bonds.

After Ti-doping, we see the significant contribution of Ti-3 3 in the unoccupied level. That means Ti atom is in the cationic state and can accept electrons from other atoms as well. We may notice just below the Fermi level some hybridization between $\mathrm{Ti}$ and $\mathrm{C}$ atoms. As hydrogen molecules are added one after another, the vacant $d$ orbital of $\mathrm{Ti}$ gets gradually filled up, and as a result of that the unoccupied states of $\mathrm{Ti}^{+}$(as shown in DOS of $\left.\mathrm{Ti} @ \mathrm{BC}_{4} \mathrm{~N}\right)$ becomes de-populated in $\mathrm{Ti} @ \mathrm{BC}_{4} \mathrm{~N}+4 \mathrm{H}_{2}$ at the cost of the $\mathrm{H}-1 s$ peak to grow (see figure 5). This is also apparent from the molecular orbital plot of $\mathrm{Ti} a \mathrm{BC}_{4} \mathrm{~N}+4 \mathrm{H}_{2}$ where we can clearly see that we need two unoccupied $d$-orbital, one for molecular bonding with hydrogen and the other to bind the metal to the nanotube (figure $6 b$ ). 

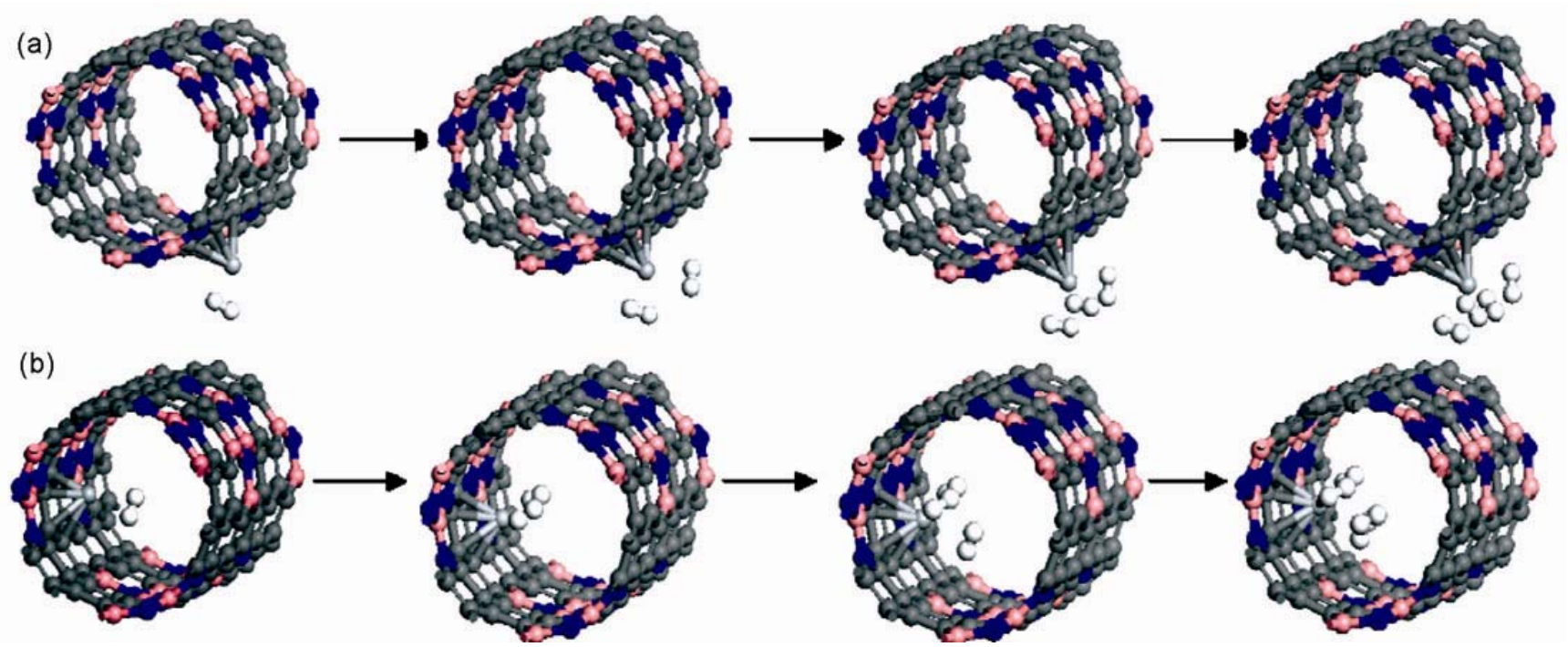

Figure 3 (Colour online). Consecutive adsorption of $\mathrm{H}_{2}$ molecules in (a) exohedral $\mathrm{Ti} @ \mathrm{BC}_{4} \mathrm{~N}$ nanotube and (b) endohedral Ti $@ \mathrm{BC}_{4} \mathrm{~N}$ nanotube. Pink ball = B, blue ball = N, dark ash ball $=\mathrm{C}$, light ash ball $=\mathrm{Ti}$, white ball $=\mathrm{H}$.
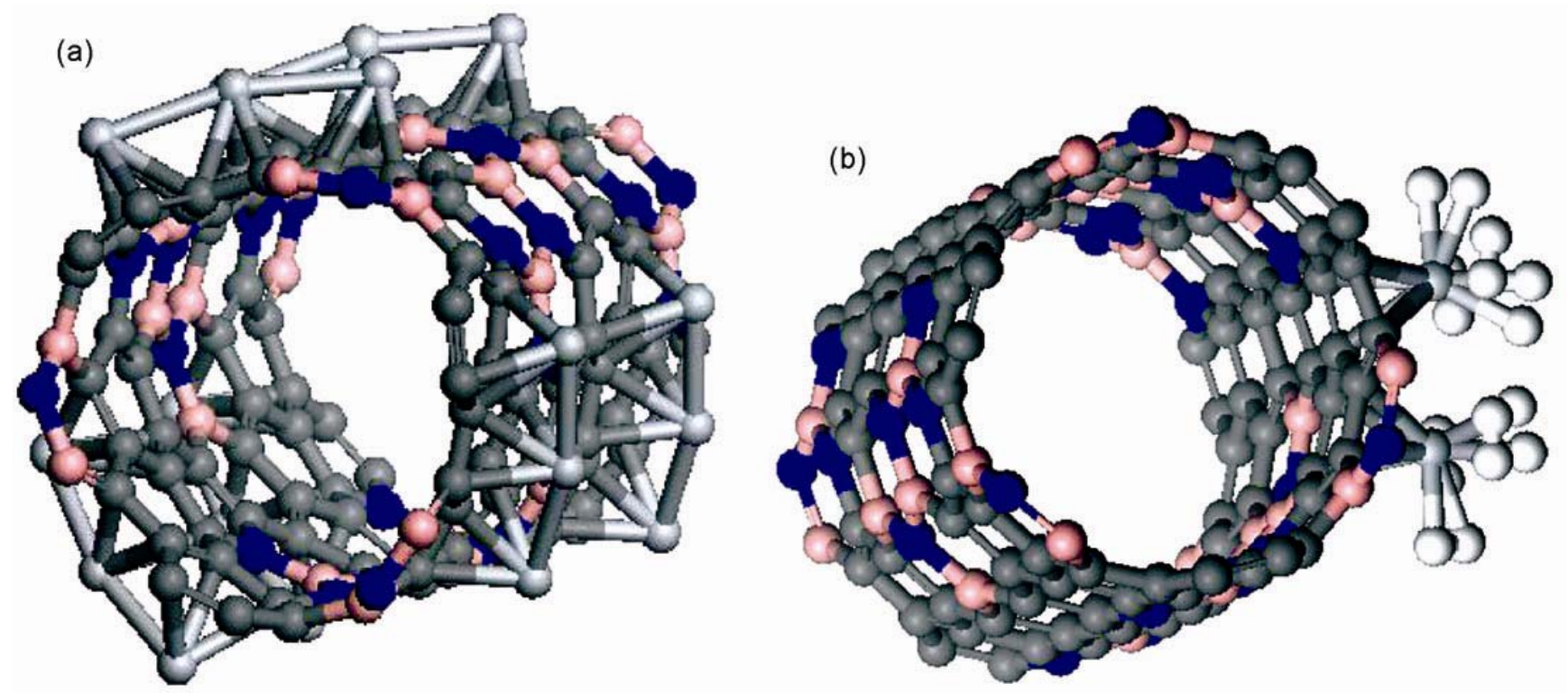

Figure 4 (Colour online). (a) Ball and stick model for optimized structure of $\mathrm{Ti}_{18} @ \mathrm{BC}_{4} \mathrm{~N}$ and (b) two Ti atoms placed on the two neighbouring $6 \mathrm{C}$ hexagonal faces of $\mathrm{BC}_{4} \mathrm{~N}$ nanotube, along with $4 \mathrm{H}_{2}$ molecules adsorbed on each Ti, to form $\mathrm{Ti}_{2} @ \mathrm{BC}_{4} \mathrm{~N}+8 \mathrm{H}_{2}$.

Table 2. Binding energy values for $\mathrm{H}_{2}$ adsorption in exo- and endo-hedral Ti@ $@ \mathrm{BC}_{4} \mathrm{~N}$ nanotubes.

\begin{tabular}{|c|c|c|c|}
\hline \multicolumn{2}{|c|}{$\mathrm{BE}(\mathrm{eV})$ for exohedral molecular $\mathrm{H}_{2}$ adsorption } & \multicolumn{2}{|c|}{$\mathrm{BE}(\mathrm{eV})$ for endohedral molecular $\mathrm{H}_{2}$ adsorption } \\
\hline System & $\mathrm{BE}$ value $\left(\mathrm{eV} / \mathrm{H}_{2}\right.$ molecule $)$ & System & $\mathrm{BE}$ value $\left(\mathrm{eV} / \mathrm{H}_{2}\right.$ molecule $)$ \\
\hline $\mathrm{Ti} @ \mathrm{BC} 4 \mathrm{~N}+1 \mathrm{H}_{2}$ & $-0 \cdot 66$ & $\mathrm{Ti} @ \mathrm{BC} 4 \mathrm{~N}+1 \mathrm{H}_{2}$ & $-0 \cdot 48$ \\
\hline $\mathrm{Ti} @ \mathrm{BC} 4 \mathrm{~N}+2 \mathrm{H}_{2}$ & $-0 \cdot 67$ & $\mathrm{Ti} @ \mathrm{BC} 4 \mathrm{~N}+2 \mathrm{H}_{2}$ & $-0 \cdot 63$ \\
\hline $\mathrm{Ti} @ \mathrm{BC} 4 \mathrm{~N}+3 \mathrm{H}_{2}$ & $-0 \cdot 58$ & $\mathrm{Ti} @ \mathrm{BC} 4 \mathrm{~N}+3 \mathrm{H}_{2}$ & $-0 \cdot 18$ \\
\hline $\mathrm{Ti} @ \mathrm{BC} 4 \mathrm{~N}+4 \mathrm{H}_{2}$ & $-0 \cdot 40$ & $\mathrm{Ti} @ \mathrm{BC} 4 \mathrm{~N}+4 \mathrm{H}_{2}$ & $-0 \cdot 04$ \\
\hline
\end{tabular}


Table 3. Bond length details of Ti-C, Ti-H and $\mathrm{H}-\mathrm{H}$ in $\mathrm{Ti} @ \mathrm{BC}_{4} \mathrm{~N}$ nanotube.

\begin{tabular}{|c|c|c|c|c|c|c|}
\hline \multirow{2}{*}{$\begin{array}{l}\text { Consecutive number } \\
\text { of hydrogen } \\
\text { adsorption } \\
\text { at Ti@ } \mathrm{BC}_{4} \mathrm{~N}\end{array}$} & \multicolumn{3}{|c|}{$\begin{array}{l}\text { Consecutive adsorption of } \mathrm{H}_{2} \text { molecules in } \\
\text { exohedral Ti@ } \mathrm{BC}_{4} \mathrm{~N} \text { nanotube }\end{array}$} & \multicolumn{3}{|c|}{$\begin{array}{l}\text { Consecutive adsorption of } \mathrm{H}_{2} \text { molecules in } \\
\text { endohedral Ti@ } \mathrm{BC}_{4} \mathrm{~N} \text { nanotube }\end{array}$} \\
\hline & $\begin{array}{c}\mathrm{Ti}-\mathrm{C} \\
\text { distance }(\AA)\end{array}$ & $\begin{array}{c}\text { Ti-H } \\
\text { distance }(\AA)\end{array}$ & $\begin{array}{c}\mathrm{H}-\mathrm{H} \\
\text { distance }(\AA)\end{array}$ & $\begin{array}{c}\mathrm{Ti}-\mathrm{C} \\
\text { distance }(\AA)\end{array}$ & $\begin{array}{c}\text { Ti-H } \\
\text { distance }(\AA)\end{array}$ & $\begin{array}{c}\mathrm{H}-\mathrm{H} \\
\text { distance }(\AA)\end{array}$ \\
\hline $\mathrm{Ti} @ \mathrm{BC}_{4} \mathrm{~N}+1 \mathrm{H}_{2}$ & $\begin{array}{ll}2 \cdot 31 & 2 \cdot 22 \\
2 \cdot 31 & 2 \cdot 20 \\
2 \cdot 30 & 2 \cdot 48\end{array}$ & 1.98 & $0 \cdot 82$ & $\begin{array}{l}2 \cdot 382.26 \\
2 \cdot 172 \cdot 22 \\
2 \cdot 372 \cdot 32\end{array}$ & $2 \cdot 04$ & $0 \cdot 80$ \\
\hline $\mathrm{Ti} @ \mathrm{BC}_{4} \mathrm{~N}+2 \mathrm{H}_{2}$ & $\begin{array}{ll}2 \cdot 31 & 2 \cdot 24 \\
2 \cdot 35 & 2 \cdot 26 \\
2 \cdot 32 & 2 \cdot 48\end{array}$ & 1.951 .94 & 0.830 .83 & $\begin{array}{l}2 \cdot 332 \cdot 34 \\
2 \cdot 642 \cdot 29 \\
2 \cdot 322 \cdot 16\end{array}$ & 1.871 .87 & 0.870 .87 \\
\hline $\mathrm{Ti} @ \mathrm{BC}_{4} \mathrm{~N}+3 \mathrm{H}_{2}$ & $\begin{array}{ll}2 \cdot 33 & 2 \cdot 31 \\
2 \cdot 40 & 2 \cdot 24 \\
2 \cdot 32 & 2 \cdot 50\end{array}$ & $\begin{array}{c}1.831 .93 \\
1.85\end{array}$ & $\begin{array}{c}0 \cdot 880 \cdot 88 \\
0 \cdot 82\end{array}$ & $\begin{array}{l}2 \cdot 342 \cdot 35 \\
2 \cdot 302 \cdot 31 \\
2 \cdot 342 \cdot 18\end{array}$ & $\begin{array}{c}2.051 .88 \\
1.88\end{array}$ & $\begin{array}{c}0.790 \cdot 85 \\
0.84\end{array}$ \\
\hline $\mathrm{Ti} @ \mathrm{BC}_{4} \mathrm{~N}+4 \mathrm{H}_{2}$ & $\begin{array}{ll}2 \cdot 31 & 2 \cdot 30 \\
2 \cdot 43 & 2 \cdot 27 \\
2 \cdot 32 & 2 \cdot 51\end{array}$ & $\begin{array}{l}1.931 .91 \\
1.931 .91\end{array}$ & 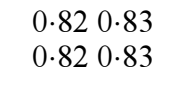 & $\begin{array}{ll}2 \cdot 35 & 2 \cdot 35 \\
2 \cdot 30 & 2 \cdot 30 \\
2 \cdot 34 & 2 \cdot 19\end{array}$ & $\begin{array}{l}4.512 .08 \\
1.871 .88\end{array}$ & $\begin{array}{l}0.750 \cdot 79 \\
0.850 \cdot 84\end{array}$ \\
\hline
\end{tabular}
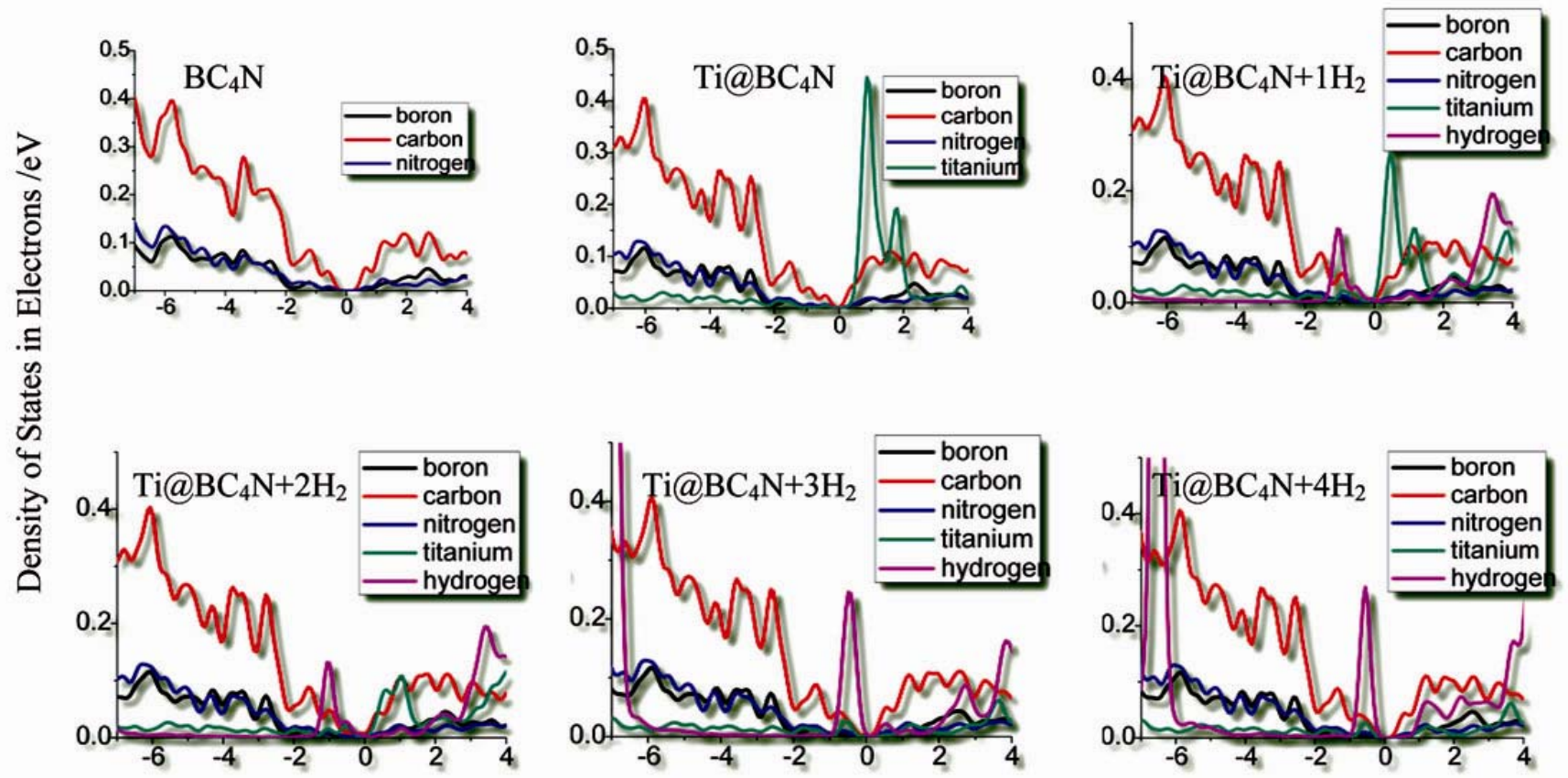

Energy in eV

Figure 5 (Colour online). Partial densities of states projected on to the individual constituents for (i) $\mathrm{BC}_{4} \mathrm{~N}$, (ii) $\mathrm{Ti} @ \mathrm{BC}_{4} \mathrm{~N}$, (iii) $\mathrm{Ti} @ \mathrm{BC}_{4} \mathrm{~N}+1 \mathrm{H}_{2}$, (iv) Ti@ $\mathrm{BC}_{4} \mathrm{~N}+2 \mathrm{H}_{2}$, (v) Ti@ $\mathrm{BC}_{4} \mathrm{~N}+3 \mathrm{H}_{2}$ and (vi) $\mathrm{Ti} @ \mathrm{BC}_{4} \mathrm{~N}+4 \mathrm{H}_{2}$.

\subsection{Desorption kinetics}

A very important issue for a material to be used for hydrogen storage is its desorption kinetics and thermal stability at higher temperature. In order to test system stability and hydrogen desorption, we have performed $a b$ initio molecular dynamics (MD) simulation on $\mathrm{Ti} @ \mathrm{BC}_{4} \mathrm{~N}+4 \mathrm{H}_{2}$ sys- tem which is heated in steps first from $0-300 \mathrm{~K}$ and then from $300-500 \mathrm{~K}$ with 1 fs time step using Nose algorithm (Nose 1984). We have noticed that at $300 \mathrm{~K}$ the system remains stable with all four $\mathrm{H}_{2}$ molecules attached on Ti atom in $\mathrm{Ti} a \mathrm{BC}_{4} \mathrm{~N}$ nanotube, whereas hydrogen starts desorbing from $\mathrm{Ti} @ \mathrm{BC}_{4} \mathrm{~N}$ nanotube at a temperature around $500 \mathrm{~K}$ (figure 7). By carrying out ab initio mole- 
(a)
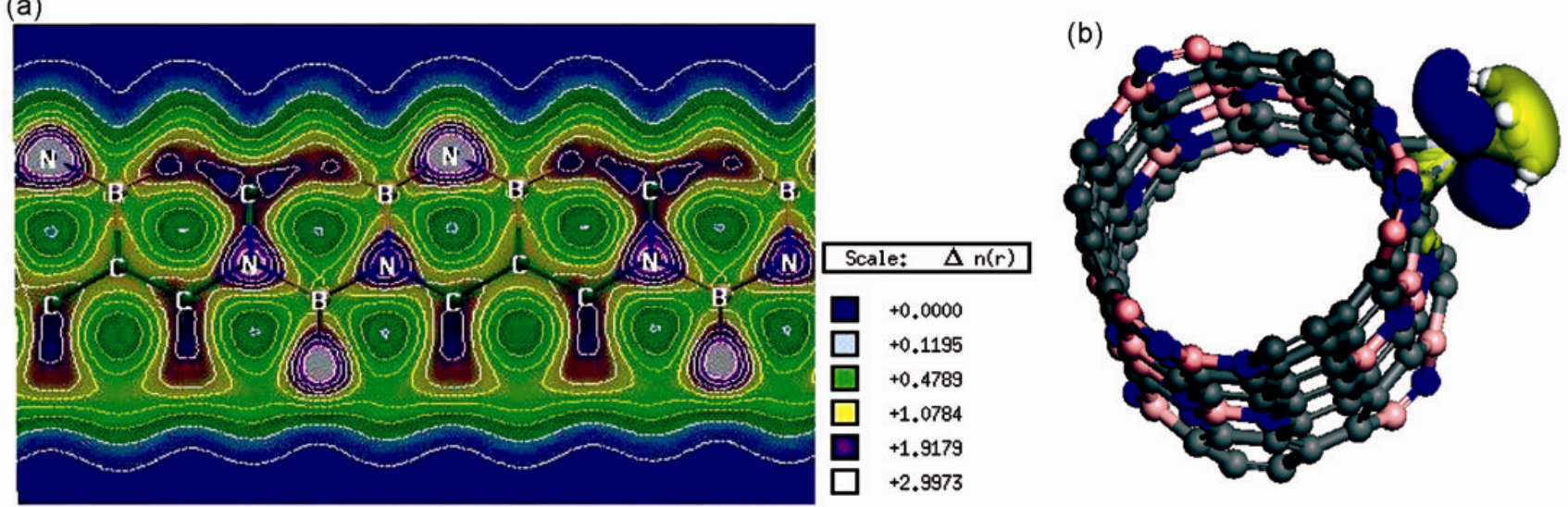

Figure 6 (Colour online). (a) Charge density contour plot for pure $\mathrm{BC}_{4} \mathrm{~N}$ nanotube $(010)$ plane, showing the $\mathrm{B}-\mathrm{N}, \mathrm{B}-\mathrm{C}$, and $\mathrm{C}-\mathrm{N}$ bonds in comparison with the $\mathrm{C}-\mathrm{C} \pi$ bond and (b) Ti- $d$ orbital hybridized with the $1 s$ orbitals of $4 \mathrm{H}_{2}$ complex and the $2 p$ orbitals of $6 \mathrm{C}$ carbon hexagon, in $\mathrm{Ti} @ \mathrm{BC}_{4} \mathrm{~N}+4 \mathrm{H}_{2}$.
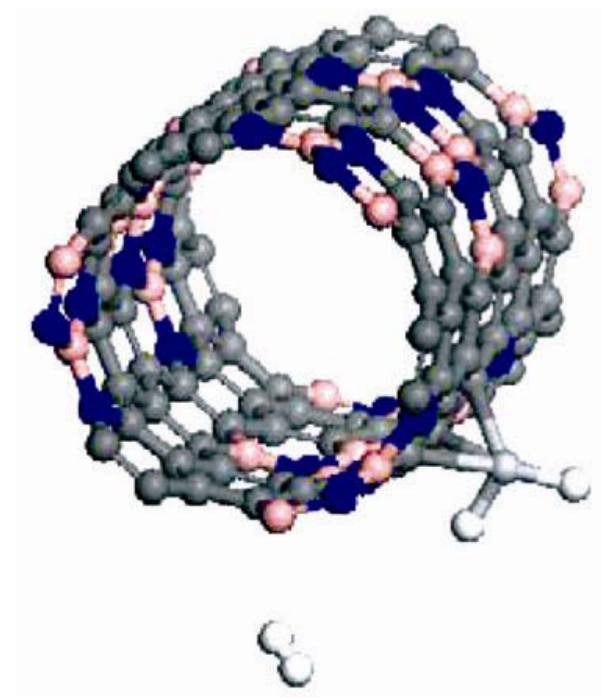

Figure 7 (Colour online). Desorption of hydrogen from $\mathrm{Ti} @ \mathrm{BC}_{4} \mathrm{~N}+4 \mathrm{H}_{2}$ at $500 \mathrm{~K}$.

cular dynamics (MD) to this 153 atoms system for 5.5 ps MD run, we get statistically meaningful values for desorption temperature. It does suggest that the system is quite stable at room temperature and it is possible to extract $\mathrm{H}_{2}$ molecules without breaking the Ti-C bonding from the host system $\mathrm{Ti} @ \mathrm{BC}_{4} \mathrm{~N}$ at a relatively moderate temperature around $500 \mathrm{~K}$.

\section{Conclusions}

In summary, we investigated the ground state structure and stability of exohedral as well as endohedral Ti-decorated $(6,6)$ armchair $\mathrm{BC}_{4} \mathrm{~N}$ nanotube which can be considered as an amalgam of carbon and $\mathrm{B}-\mathrm{N}$ nanotubes. Each sitting on $6 \mathrm{C}$ hexagonal face of the nanotube absorbs up to $4 \mathrm{H}_{2}$ molecules. The entire structure remains stable up to $500 \mathrm{~K}$ where $\mathrm{H}_{2}$ comes out without breaking the $\mathrm{Ti}-\mathrm{C}$ bonding. The desorption temperature and kinetics are quite favourable, at the same time, the gravimetric efficiency corresponding to full $\mathrm{Ti}$ coverage turns out to be $\sim 5.6 \mathrm{wt} \%$. Thus Ti-decorated $\mathrm{BC}_{4} \mathrm{~N}$ nanotube shows more promise than conventional carbon nanotube and boron nitride nanotube for the purpose of $\mathrm{H}_{2}$ storage in a nanostructure material.

Currently we are exploring the possibility of jacking up the gravimetric efficiency to $\sim 8 \mathrm{wt} \%$, retaining the desorption characteristics in tact, by flattening the nanotube and forming a graphene-like planar structure with TM decoration on both sides (Bhattacharya et al, to be published). While hydrogenation of graphene has already been suggested by earlier workers (Sluiter and Kawazoe 2003; Boukhvalov et al 2008), such a novel Ti-decorated planar $\mathrm{BC}_{4} \mathrm{~N}$ structure is expected to yield a breakthrough in the area of hydrogen storage in nanomaterials.

\section{Acknowledgements}

The authors would like to thank Prof. Umesh V. Waghmare for many helpful discussions, and to Dr Mousumi Upadhyay-Kahaly for providing the structural details of $(6,6) \mathrm{BC}_{4} \mathrm{~N}$ nanotube.

\section{References}

Barman S, Sen P and Das G P 2008 J. Phys. Chem. C112 9963

Bhattacharya S, Majumder C and Das G P 2008 J. Phys. Chem. C (Letter) 11217487

Bhattacharya S, Majumder C and Das G P, to be published Blasé X, Rubio A, Louie S G and Cohen M L 1994 Europhys. Lett. 28335 
Blöchl P E 1994 Phys. Rev. B50 17953

Boukhvalov D W, Katsnelson M I and Lichtenstein A I 2008 PRB 7735427

Chopra N G, Luyken R J, Cherry K, Crespi V H, Cohen M L, Louie S G and Zettl A 1995 Science 69966

Darkrim F L, Malbrunot P and Tartaglia G P 2002 Int. J. Hyd. Energy 27193

David E 2005 J. Mater. Process Technol. 162-163 169

DOE report on basic research needs for hydrogen storage, http://www.sc.doe.gov/bes/hydrogen.pdf

Dillon A C and Heben M J 2001 Appl. Phys. A72 133

Dillon A C, Jones K M, Bekkedahl T A, Kiang C H, Bethune D S and Heben M J 1997 Nature (London) 386377

Hirscher M and Panella B 2007 Scr. Mater. 56809

Hohenberg P and Kohn W 1964 Phys. Rev. 136 B864

Hu Y H and Ruckenstein E 2006 Ang. Chemie. 452011

Jacoby M 2005 Chem. Eng. News 8342

Kajiura H, Tsutsui S, Kadono $\mathrm{K}$, Kakuta $\mathrm{M}$, Ata $\mathrm{M}$ and Murakami Y 2003 Appl. Phys. Lett. 821105

Kohn W and Sham L 1965 Phys. Rev. 140 A1133

Kresse G and Hafner J 1994 Phys. Rev. B49 14251

Kresse G and Furthmüller J 1996 Comput. Mater. Sci. 615

Logar N Z and Kaucic V 2006 Acta Chim. Slog. 53117

Ma R, Bando Y, Zhu H, Sato T, Xu C and Wu D $2002 \mathrm{~J}$. Am. Chem. Soc. 1247672

Meregalli V and Parrinello M 2001 Appl. Phys. A72 143

Monkhorst H J and Pack J D 1976 Phys. Rev. B13 5188

Narita I and Oku T 2002 Diamond Relat. Mater. 11945

Nose S A 1984 J. Chem. Phys. 81511

Oku T and Narita I 2002 Physica B323 216

Oku T, Naritab I, Nishiwakic A and Koid N 2004a Defect Diffusion Forum 226-228 113

Oku T, Kuno M and Narita I 2004b J. Phys. Chem. Solids 65 549

Orimo S, Nakamori Y, Eliseo J R, Züttel A and Jensen C M 2007 Chem. Rev. 1074111

Perdew J P and Wang Y 1992 Phys. Rev. B45 13244
Perdew J P, Chevary J A, Vosko S H, Jackson K A, Pederson M R, Sing D J and Fiolhais C 1992 Phys. Rev. B46 6671

Press W H, Flannery B P, Tenkolsky S A and Vetterling W T 1986 Numerical recipes (New York: Cambridge University Press) Vol. 1

Pulay P 1980 Chem. Phys. Lett. 73393

Raidongia K, Jagadeesan D, Kayaly M, Waghmare U V, Pati S K, Eswaranmoorty M and Rao C N R 2008 J. Mater. Chem. 1883

Rowsell J L C and Yaghi O M 2005 Angew. Chem. Int. Ed. 44 4670

Sakintuna B, Darkrim F L and Hirscher M 2007 Int. J. Hyd. Energy 321121

Schlappbach L and Züttel A 2001 Nature 414353

Sen R, Satishkumar B C, Govindaraj A, Harikumar K R, Raina G, Zhang J, Cheetham A K and Rao C N R 1998 Chem. Phys. Lett. 287671

Shevlina S A and Guo Z X 2006 Appl. Phys. Lett. 89153104

Shiraishi M, Takenobu T and Ata M 2003 Chem. Phys. Lett. 367633

Sluiter M H F and Kawazoe Y 2003 PRB 6885410

Struzhkin V V, Militzer B, Mao W L, Mao H K and Hemley R J 2007 Chem. Rev. 1074133

Sun Q, Wang Q and Jena P 2005 Nano Letts 51273

Tibbetts G G, Meisner C P and Olk C H 2001 Carbon 392291

Weng-Sieh Z, Cherrey K, Chopra N G, Blasé X, Miyamoto Y, Rubio A, Cohen M L, Louie S G, Zettl A and Gronsky R 1995 Phys. Rev. B51 11229

Williamson A J, Reboredo F A and Galli G 2004 Appl. Phys. Lett. 852917

Wolverton C, Siegel D J, Akbarzadeh A R and Ozolin V 2008 J. Phys.: Condens. Matter 20064228

Yagi Y, Briere T M, Sluiter M H F, Kumar V, Farajian A A and Kawazoe Y 2004 Phys. Rev. B69 075414

Yildirim T and Ciraci S 2005 Phys. Rev. Lett. 94175501

Züttel A 2003 Mater. Today 624

Züttel A 2004 Naturwissenschaften 91157 